NICE and the draft fertility guideline

\section{NICE, the draft fertility guideline and dodging the big question}

\section{J R McMillan}

\section{NICE, the draft fertility guideline and dodging the big question: should fertility treatment be provided by the NHS?}

In August of this year the National Institute for Clinical Excellence (NICE) made its draft guideline on fertility treatment available for consultation. ${ }^{1}$ As has been widely reported in the media the draft guideline recommends that the National Health Service (NHS) should provide publicly funded fertility treatment in a consistent way across England and Wales. The guideline recommends that three cycles of IVF should be available when "The woman is within the optimal range for in vitro fertilisation (that is, the woman is 23-39 years) and there is an appropriately diagnosed cause of infertility of any duration, or unexplained infertility of at least three years' duration (including mild endometriosis and mild semen abnormality" (National Institute for Clinical Excellence, ${ }^{1}$ p 35 ).

Those who need fertility treatment will celebrate the guideline, as will many fertility clinics. The guideline does not, however, address key questions that will be obvious to many. Is fertility treatment the kind of thing that ought to be available on the NHS? Will the inevitable increase in demand mean that resources are directed away from other services? Is fertility treatment really the same kind of intervention as heart or hip replacement surgery?

My view is that there are good reasons for doing what we can to help people access fertility services. Most of us will start a family and for those of us who do it is probably the most important of all of our life projects. Given that social status and wealth can be significant obstacles to many of the things that people would like to do with their lives, the fact that most of us are able to pursue this important life project is good from an egalitarian point of view. Infertility, and in particular not being able to access fertility services because of their cost, are significant inequalities because they mean that people are not able to do something of great importance to them, which is something most people can do. The NICE guideline does very little, however, in the way of producing arguments of this kind and by only considering the cost effectiveness of fertility treatment dodges the big question about publicly funded fertility treatment.

The guideline is in part an attempt to overcome the so called postcode lottery that bedevils access to fertility services in England and Wales. Although it is unfair that access to fertility services should be determined by where you live this is not the only important issue. Iffor example, one health authority began providing people with holidays in the sun so they could avoid the winter blues this would not provide a good reason for standardising access to holidays across all health authorities. Two additional considerations are the cost effectiveness and medical appropriateness of providing publicly funded fertility services. The guideline includes a bibliography of over a thousand academic papers, the majority of which are about the cost effectiveness of various fertility treatments. But it is striking that there is not a single reference to the ethics literature on the appropriateness of providing fertility treatment. In particular it is very surprising to find no mention of the work done by Burley, ${ }^{2}$ Harris, ${ }^{3} \mathrm{O}^{\prime}$ Neill, ${ }^{4}$ and Warnock ${ }^{5}$ on whether there is a positive right to assistance with reproduction.

It might be that decisions about the allocation of health care resources should be made simply upon the basis of their cost effectiveness. This position has some initial intuitive appeal but has implications that many would find counterintuitive if applied without constraint. If pregnancy is the outcome that matters for cost effectiveness then there is no obvious reason why publicly funded fertility treatment should not be provided to lesbians and single women. (For an excellent discussion of arguments for allowing lesbians and single women to access fertility services see the parliamentary library research paper by M Rickard. ${ }^{6}$ ) In fact it might be that lesbians and single women are more cost effective to treat than infertile heterosexual couples because they are less likely to have a physiological cause for their unwanted childlessness. In addition to having some counterintuitive implications cost effectiveness can be unfair. The recommendation that NHS funded in vitro fertilisation (IVF) should not be offered to women over the age of 39 is based on the fact that it is much less likely to work but it is likely that women in this group have a similar interest to younger women in being able to access IVF (National Institute for Clinical Excellence, ${ }^{1}$ p 35$)$.

The National Institute for Clinical Excellence are likely to object that their function is to provide advice to the NHS about the cost effectiveness of medical interventions. They do say that there are important social factors associated with the public funding of fertility services that go beyond the scope of the guideline, and that they are asked to provide guidance on age ranges for fertility treatment (National Institute for Clinical Excellence, ${ }^{1}$ pp 8 and 13). There are three problems with this response. First, it is odd to think that a guideline could be a useful prescription for what the NHS should do without considering the medical appropriateness of fertility treatment. It might be that the responsibility for this lies with the agency that determined the terms of reference for this guideline but in any case its value as a prescription for the NHS is undermined. Second, by recommending that publicly funded fertility treatment should be available to heterosexual couples and not, by implication, to single women and lesbians, the guideline does make social judgments. The guideline says that "for the purposes of investigation, infertility should be defined as failure to conceive after regular unprotected sexual intercourse for two years in the absence of any reproductive pathology" (National Institute for Clinical Excellence, ${ }^{1} \mathrm{p}$ 46). This definition rules the majority of lesbians and single women out of consideration. Third, the guideline does (as I will show in a moment) discuss appropriateness as well as cost effectiveness. If they are prepared to say something about this they may as well consider it more fully.

\section{IVF AS A MEDICAL NEED}

Critics of the NICE guideline are likely to suggest that fertility treatment is "less medical" than other treatments provided by the NHS. The guideline addresses this concern briefly when it claims:

The United Nations defines reproductive health as "a state of complete physical, mental, and social wellbeing and not merely the absence of disease or infirmity in 
all matters relating to the reproductive system and to its functions and processes". ... Infertility should, therefore, be considered to be a disease process worthy of investigation and treatment (National Institute for Clinical Excellence,' p 45).

Although statements by the United Nations (UN) do convey a sense of authority it is not clear how this definition will do the work that the guideline requires. The UN definition of reproductive health is quite similar to the World Health Organisation's (WHO) definition of health: "Health is a state of complete physical, mental, and social wellbeing and not merely the absence of disease or infirmity". ${ }^{7}$ All they've done is to limit the scope to reproduction.

Whereas the WHO definition is so general that it is hard to apply, the UN definition of reproductive health risks being so general that it might imply NHS funding for many things. In other words it is not obvious why we ought to adopt reproductive health as an aim for the NHS. Being unattractive can result in an organism being unable to reproduce. If reproductive health is what the NHS ought to aim at then it ought to provide ways for the unattractive to reproduce.

There is a logical problem in deriving a concept of reproductive disease from the UN definition. The UN gives a definition of reproductive health and not an account of disease-like the WHO they are clear that what they are interested in is giving a broad account of wellbeing. The guideline attempts to derive the conclusion that infertility is a disease process from a definition of reproductive wellbeing.

A better way of tackling this question is by thinking about whether or not wanting fertility treatment can be considered a "medical need". Norman Daniels has developed a theory of medical needs which attempts to explain the special authority that claims to medical assistance have. ${ }^{8}$ The basic idea is that health needs result from disease or deviation from the functional organisation typical for that organism and that they impact upon a person's equality of opportunity or chance to live in accordance with their conception of the good life. On this view fertility services look like paradigm examples of medical needs. (For more on this see my paper in Human Fertility. ${ }^{9}$ ) Not being able to reproduce when it would be typical to able to do so, and the impact this can have on the chance for people to do what they most want with their lives, satisfies both of the Daniels conditions.

I have already mentioned that if cost effectiveness is taken to be sufficient for deciding this matter then it looks like lesbian and single women should not be omitted from the guideline. It is not obvious, however, that even on the Daniels account they should not receive publicly funded fertility treatment. It is reasonable to suppose that a lesbian couple wanting assistance with reproduction will want this because it forms an important part of their conception of a good life and it is an opportunity that most people have which they do not. Furthermore, being able to reproduce when they are of childbearing age is functionally something that they ought to be able to do. So on one reading a lesbian couple could have a medical need for fertility treatment.

For some people this conclusion will be a reductio ad absurdum of the NICE recommendation. It is patently absurd to provide publicly funded fertility services to lesbian couples so publicly funded fertility services are absurd. For those who think that publicly funded fertility treatment for lesbians and single women is reasonable, it will show that NICE are in effect making unfair social discriminations under the guise of cost effectiveness.

\section{CONCLUSION}

Given that fertility treatment appears to meet a medical need, at least on the Daniels account, why is there any controversy about the guideline? Part of the explanation is, as Richard Ashcroft has pointed out, because of the social issues associated with fertility treatment. ${ }^{10} \mathrm{~A}$ second explanation is that when fertility treatment is compared to other medical interventions it is, irrespective of how it fares on the Daniels account of need, different from other medical treatments. If an effect of standardised access to fertility treatment is that resources have to be directed away from other services, questions about the medical appropriateness are likely to be raised. If better access to fertility services means that access to some surgical services is made worse then few would be bold enough to endorse this priority.

The guideline is expected to be finalised by February 2004 and it will be interesting to see whether its authors grasp the nettle and provide some good arguments for the public funding of fertility treatment.

J Med Ethics 2003;29:313-314

Correspondence to: J R McMillan, Department of History and Philosophy of Science, University of Cambridge, Free School Lane, Cambridge CB2 3RH, UK; jm439@cam.ac.uk

\section{REFERENCES}

1 National Collaborating Centre for Women's and Children's Health, commissioned by NICE. Fertility guideline: assessment and treatment for people with fertility problems (second draft). http://www.nice.org.uk (accessed 18 Sept 2003)

2 Burley J. The price of eggs: who should bear the costs of fertility treatments? In: Harris J, Holm S eds. The future of human reproduction. Oxford: Oxford University Press, 2000.

3 Harris J. Rights and reproductive choice. In: Harris J, Holm S, eds. The future of human reproduction. Oxford: Oxford University Press, 2000.

4 O'Neill O. Autonomy and trust in bioethics. Cambridge: Cambridge University Press, 2002.

5 Warnock M. Making babies: is there a right to have children? Oxford: Oxford University Press, 2002.

6 Rickard M. Is it medically legitimate to provide assisted reproductive treatments to fertile lesbians and single women? Department of the parliamentary library, parliament of Australia. Research paper no 23 2000-01 http:// www.aph.gov.au/library/pubs/rp/2000-01/ 01RP23.htm (accessed 8 Oct 2003).

7 World Health Organisation. Constitution of the World Health Organisation: preamble. International Health Conference. New York, USA, 1946 Jun 19-22.

8 Daniels N. Just health care. Cambridge: Cambridge University Press, 1985.

9 McMillan J. Allocating fertility services by medical need. Hum Fert 2001;4:11-13.

10 Ashcroft $\mathbf{R}$. In vitro fertilisation for all? $B M$ 2003:327:51 1-12. 